Journal of Research in Technical Careers

December 2019, Vol. 3, No. 2.

(C) Author(s)

\title{
A Case Study of the Development of a Career Academy: Good Intentions Not Enough?
}

\author{
Victor M. Hernández-Gantes, Edward C. Fletcher Jr., Sasha Keighobadi \\ University of South Florida
}

\begin{abstract}
The purpose of this study was to explore how a career academy featuring an information technology (IT) theme approached the adoption of the model and the particular curricular focus. We used a case study design to explore the experiences of school personnel and community partners associated with the implementation of the career academy. We found that growing enrollment in the local district was a major driver to pursue small school designs as an alternative to the traditional high school comprehensive model. The small school size associated with small learning communities was valued by stakeholders and used to adopt and implement a career academy around a technology curricular theme. Another factor in the adoption decision was the availability of existing building infrastructure in the community. While the premises of the career academy model appeared to be a good fit in the district and community, we also found that good intentions are not enough to guarantee consistent fidelity throughout the career academy implementation. When new crises arise, input from all stakeholders may be shortchanged and decisions can turn into a top-down approach.
\end{abstract}

Keywords: career academies, career and technical education, small learning communities, school restructuring, educational leadership

\section{Introduction}

Enhanced college and career readiness has become a top priority in the United States (US) over the past two decades. The need was spearheaded by reports that high school graduates lack the preparation needed for successful transition to college and work in today's economy, especially in fields related to science, technology, engineering, and mathematics (STEM) (Carnevale, Smith, \& Strohl, 2010; Loera, Nakamoto, Oh, \& Rueda, 2013). This trend prompted educators and policymakers to call for alternative approaches to promote college and career readiness (Hernandez-Gantes \& Fletcher, 2013). In this context, the career academy model provided a platform for promising applied curricula, and its popularity has grown dramatically over the past decade (Fletcher \& Cox, 2012; Stone, 2017). In recent years, it has been estimated that there are more than 7,000 career academies in the US with a combined student enrollment of about one million students (Bitterman, Gray, \& Goldring, 2013). The popularity of the career academy model stems 
from decades of implementation and extensive evidence on the impact of participation leading to reduced dropout rates, improved attendance, increased academic course-taking and interpersonal skills, and positive labor market outcomes (Kemple, 2008; Stern, Dayton, \& Raby, 2010).

A career academy is commonly defined as a small learning community that is often found within a larger high school, although they can also operate as stand-alone schools. These small learning communities offer rigorous academics in the context of a careerrelated theme such as business, health sciences, and technology (Stern et al., 2010). In addition, the implementation premises also include work-based learning experiences requiring partnerships with business and industry (Hernandez-Gantes, Jenkins, \& Fletcher, 2017; Stern et al., 2010). As such, national organizations like the National Academy Foundation (NAF) and the National Career Academy Coalition (NCAC) have supported schools and districts with the adoption and implementation of career academies. However, opportunities to receive implementation support from national organizations may be seen as a "quick fix" leading to rushed adoption and uneven model implementation in many cases (Hernandez-Gantes, 2016; Conchas \& Clark, 2002). That is, in the decision-making process, the adoption of the career academy model may be taken as a one-size-fits-all framework that may not necessarily fit the needs of each community. The adoption process may be also viewed as a checklist including expected model components, but falling short on the fidelity of implementation when evaluated against national standards of practice. To be sure, in some cases the adoption of the initial career academy design may be wellintentioned, but it may require adaptation along the way (Conchas \& Clark, 2002). In this regard, although there is a growing body of evidence about participation outcomes associated with career academies, we know very little about the decision-making processes leading to the adoption and/or adaptation of the model.

Under these premises, the purpose of this study was to explore how a career academy approached the adoption of the model and the curricular theme on information technology (IT). We were also interested in the contextual role of the community at large and about the design considerations relevant to the local needs of students to promote college and career readiness. The selected career academy is affiliated with NAF and is located in a low-income area with a majority Latino(a) population. As such, the career academy and the community context provided the grounds for the inquiry based on three complementary research objectives. We sought to document: (a) the critical considerations for the adoption of the career academy model featuring an information technology (IT) theme, (b) the design features viewed as fundamental for promoting college and career readiness, and (c) the role of the community context in adopting and shaping the career academy model.

\section{Conceptual Framework}

We used a framework grounded in three conceptual strands: college and career readiness, small learning communities and career academies, and principles of school restructuring. 
The Push for College and Career Readiness. The push for college and career readiness as a driver for change evolved out of steady reports noting high school students were not appropriately prepared for further education and work (Carnevale, Smith, \& Strohl, 2010; Loera, Nakamoto, Oh, \& Rueda, 2013). Thus, improving college and career readiness of students has become a top priority in schools and districts and has served as a driver for change (Hernandez-Gantes, Keighobadi, \& Fletcher, 2018; Fletcher, Warren, \& Hernandez-Gantes, 2018). To clarify the term, based on extensive research, Conley (2012) suggested that students are college and career-ready when they are qualified to successfully complete entry-level college coursework and/or a career-oriented program. He noted, however, that the nature of a student's postsecondary interests should define the specific preparation necessary for postsecondary transitions. Building upon these premises, Stone and Lewis (2012) further defined college and career readiness in the context of career and technical education (CTE) as the extent of high school graduates' academic knowledge, as well as their employability and technical skills.

Regarding academic knowledge, it has been noted that CTE students should have mastery of core academics (i.e., science, mathematics, and language arts) to ensure readiness for postsecondary education, without the need for remediation. One indicator of readiness is enrollment in rigorous academic coursework that is aligned to lower level postsecondary coursework and experiences (Karp, Calcagno, Hughes, Jeong, \& Bailey, 2007). Regarding career readiness, students also need employability and technical skills to be successful in their chosen careers (Achieve, 2016). Employability skills include critical thinking skills (i.e., creative and problem solving), personal responsibility skills (i.e., responsibility, integrity, and self-management), and technological skills (i.e., innovation and information management) (Partnership for $21^{\text {st }}$ Century Skills, 2011; Secretary’s Commission on Achieving Necessary Skills, 1991; Stone \& Lewis, 2012). Technical skills refer to the unique knowledge, skills, and dispositions needed in specific fields. To that end, students who obtain industry certifications and engage in work-based learning experiences may be able to demonstrate certain levels of technical skill attainment in specific occupational areas.

With this backdrop, schools need a shared understanding of readiness to meet the needs of students regarding transitions to college and careers. As such, the term is now widely used across the country, but it is often interpreted in a variety of ways or defined with a narrow emphasis on college preparation (Achieve, 2016; National Center on Education and the Economy, 2007; National Center for Public Policy and Higher Education, 2004; Stone \& Alfeld, 2006). To this end, for districts and schools interested in promoting students' college and career readiness, they should agree on a related definition taking into consideration the local reality of labor market needs for sustainable adoption and implementation of related programs (Barton, 2006; Cappelli, 2008; Symonds, Schwartz, \& Ferguson, 2011).

Small Learning Communities and Career Academies. The term "small learning communities" refers to a variety of school structures and designs, including career academies (or schools within a school) and magnet programs, with an enrollment range of 600 to 900 students (Kuo, 2010). Schools with small student populations, such as career 
academies, often show reduced dropout rates, increased attendance, and higher graduation rates (Page, Layzer, Schimmenti, Bernstein, \& Horst, 2002). Students in smaller learning communities often report having an increased sense of personalization and belonging, lower levels of school vandalism, and feeling of safety in the school community (Kuo, 2010; Page et al., 2002). Operationally, the career academy model bridges the premises of small learning communities, the positive elements of school culture, and an emphasis on learning in specific occupational contexts to enhance the schooling experience (Castellano, Sundell, Overman, \& Aliaga, 2012; Hernandez-Gantes \& Brendefur, 2003).

There are three key design elements of career academies, including the use of occupational curricular themes, a focus on the integration of academic and technical content, and student engagement in work-based learning experiences (NAF, 2017b). The use of occupational themes (e.g., IT) serves as an anchor for identity development for students, school staff, and community partners (Newmann \& Wehlage, 1995; Stipanovic, Lewis, \& Stringfield, 2012). Further, career academies following standards of practice are expected to focus on the integration of academic and technical curricula through crosscollaboration among teaching staff (NAF, 2017a). In turn, student participation in workbased learning experiences related to the underlying curricular theme are also expected to promote student college and career readiness. Work-based learning experiences require career academies to develop partnerships with local employers in the community (Fletcher et al., 2018; NAF, 2017a).

Extensive research and evaluation data have shown that participation in career academies has resulted in positive academic and employment outcomes for students (Kemple, 2008; Stern et al., 2010). There is also evidence indicating that career academy students perform as well as their counterparts in college preparatory tracks, while a higher number of career academy students have a transitional plan upon graduation from high school (Kemple, 2008; Kemple \& Snipes, 2000; Silverberg, Warner, Fong, \& Goodwin, 2004). In general, it has been found that career academies attract students sharing similar interests, providing the conditions for establishing school communities that are highly successful in promoting college and career readiness (Hernandez-Gantes et al., 2018). However, as the concept of career academies has grown in popularity, the interface of local conditions and culturally relevant leadership is often missing, especially in urban settings, with varying results in the quality of implementation.

Principles of School Restructuring. To better understand how academies operate from a holistic perspective, research on school restructuring provides a conceptual foundation based on principles associated with successful change and sustainability (Hernández-Gantes, Phelps, Jones, \& Holub, 1995; Newmann \&Wehlage, 1995; Resnick \& Hall, 1998; Ryan, 2011). Principles of school restructuring are helpful as a frame of reference for exploring the nature of organizational program structures of career academies in terms of development and the alignment of curriculum, implementation, and local conditions as a system. First, successful school restructuring calls for a shared consensus on goals and vision, which has been found to be essential for effective implementation and student success (Adelman \& Taylor, 2003; NCAC, 2013; Newmann \& Wehlage, 1995). This is important because one issue with the rising popularity of career academies is the 
rush to embrace the model without a shared stakeholder understanding of organizational purpose and vision (Hernandez-Gantes \& Fletcher, 2013). Additionally, there must be a consensus on the nature of curriculum design and instructional strategies to support the school purpose and ensure buy-in of all stakeholders. Thus, in a successful career academy, the curriculum must be organized under a coherent structure and emphasize applied strategies that everyone-administrators, teachers, and other staff-agrees to. The challenge for instructors is to bridge teaching and learning in ways that are appropriate for high school students and the nature of the thematic context, such as IT (NCAC, 2013).

Career academies require complex organizational supports to remain viable and relevant (Finch \& Crunkilton, 1999). Examples of organizational supports may include: student services and guidance (e.g., career awareness and exploration), professional development opportunities, planning time, support with curricular integration; and administrative supports such as scheduling, funding, appropriate equipment and facilities (Hernandez-Gantes \& Blank, 2009; Hernandez-Gantes \& Brendefur, 2003; NCAC, 2013). Finally, when implementing career academies, external supports must be considered. External factors may include partnering with local employers, meeting occupational standards, and navigating district and state directives (Finch \& Crunkilton, 1999; NCAC, 2013). Related research has suggested career and technical programs with established partnerships tend to perform better compared to sites with limited or no external partners (Alfeld, Charner, Johnson, \& Watts, 2013).

Based on these conceptual strands, we posited that when embracing the career academy model, stakeholders should have a shared understanding of the premises of small learning communities, a common agreement about the need for adopting alternative designs, and concurrence on the vision for specific implementation features. We also posited that the community context played a role in the adoption and implementation of the career model.

\section{Methods}

Research Design. To conduct the study, we followed a qualitative case study design to explore the experiences of school personnel and community partners associated with the implementation of the career academy model (Stake, 2006). The case study approach allowed the documentation of thick and rich descriptive information about the setting in which the high school IT academy was implemented. According to Stake (2006), "qualitative case researchers focus on relationships connecting ordinary practice in natural habitats to a few factors and concerns of the academic disciplines" (p. 10). Thus, in this project we studied an IT academy operating within unique contexts (i.e., community and school district) and at a certified level according to the NAF standards of practice. Pseudonyms are used in place of participant and school names as well as locations. The study was approved by the University of South Florida's Institutional Review Board (IRB).

The Case: Victory Academy. Victory was a certified wall-to-wall (whole school) NAF IT themed magnet academy, located in an urban area within the western region of the United States. The academy was comprised of approximately 325 students with 16 fulltime teachers in a school district of 24,000 students. Student admission into the magnet 
school was based on an application system. The school did not admit students based on competitive admissions criteria (e.g., essays, GPAs, interviews, or test scores) but instead had an open enrollment policy to ensure equity and inclusion of students regardless of background. The school district did not have transportation for students but encouraged students to ride the public transportation system. The ethnic and racial backgrounds of students at Victory Academy were as follows: 92\% Latino(a), 4\% Asian, 2\% African American/Black, and 2\% White. 52\% of students were female and 48\% male. Eighty-nine percent of the student population was economically disadvantaged.

The school had a focus on filmmaking with students taking courses related to digital video media production, computer programming and game design, and digital arts and graphic design. All students were issued laptops for the full four years of their schooling. Ninety-six percent of seniors in 2017 graduated within four years from Victory Academy, whereas the graduation rate for the school district was 77\%. Fifty-four percent of twelfth graders participated in advanced placement courses, and 62\% successfully passed at least one exam.

The academy was selected for this study because of its IT curricular theme affiliation with the NAF network, and historical development based on a small school design. The IT focus was on technology broadly defined, with a current emphasis on videography. Victory Academy adopted the operation of a small school around 2000, and is currently rated as "certified" by NAF. The NAF model seeks to promote college and career readiness within the context of occupational themes and postsecondary preparation through customized support to help academies improve and grow (NAF, 2014). The NAF rates academies on five levels of implementation using the following hierarchy from highest to lowest: distinguished, model, certified, member, and under review.

Data Sources and Participants. Data for the current study was collected during a fourday site visit. The academy principal agreed to provide access to the school and assist with the coordination of interviews with district and school administrators, school board members, IT and core academic teachers, school counselors, parents, staff, postsecondary, business and industry, and community partners. Interview participants represented a convenience sample selected for their institutional knowledge of the district/school (e.g., administrators, school staff) or their interactions with the academy such as parents and external partners. We collected implementation data through the review and analysis of school and academy documents, classroom observations, and interviews with administrators, faculty, staff, and school partners. For document review and analysis, we collected documents pertaining to the structure and implementation of the NAF IT Academy model. Victory Academy assembled these items in an electronic binder that included documentation and evidence of enacting the NAF standards related to academy development and structure, advisory board, curriculum and instruction, and work-based learning.

During the site visit, we engaged in 10 classroom observations to understand the instructional environments, teaching and learning processes, and types and levels of assessments administered in the academy. We used a protocol to document our observations. In addition, we conducted 21 semi-structured interviews with 28 participants. 
The interviews were with district personnel including the associate superintendent and director-level staff ( $n=6)$, school administrators $(n=2)$, school board member $(n=1)$, IT and core academic teachers $(n=11)$, school counselor $(n=1)$, parents $(n=3)$, support staff $(n=2)$, and local agencies (e.g., Upward Bound) to support student transitions to postsecondary education $(n=2)$. Individual interviews lasted approximately 60 minutes. After pilot testing the interview protocol, we conducted data collection about the purpose of the program, curriculum and instruction, and internal and external supports. To reach depth in the interview process, we used probes for elaboration of insights or to elicit clarifying examples in each of the areas of interest.

Data Analysis. All interviews were audio-recorded and transcribed verbatim. All data were analyzed using thematic content analysis to capture contextual factors underlying program implementation (Boyatzis, 1998). We then identified recurring themes following a process beginning with a review of the transcripts in their entirety to get a sense of the whole in terms of how participants talked about their experience. We continued re-reading the transcribed interviews and demarcating transitions in meaning in the content of the text utilizing a lens driven by research questions. Next, we reflected on and discussed the meaning of stakeholders' insights to examine revelatory content noted within each transcript as well as across participants' experiences. In addition, we synthesized the themes into statements seeking to accurately represent the perspectives of the interview participants (Wertz, 2005). Finally, we used data triangulation strategies by analyzing multiple data sources (i.e., the curricular documents from the electronic binder, classroom observation notes, and individual interviews) to establish cross-data consistency. From the curricular documents we verified the nature and structure of career pathways associated with IT, while classroom observations gave us an idea of instructional emphasis and integration of academic and technical content.

\section{Findings}

Victory City, where the school is located, was incorporated in the late 1800s and has a rich history of diversity rooted in Latino(a) heritage visible everywhere through street names and landmarks. Today, the city's population is predominantly Latino(a) (70\%), followed by White residents (12\%), Asians (9\%), and African Americans (7\%). The median income for the city is about $\$ 50,000$ and a poverty rate of $22 \%$. In the Victory Academy context, the majority of students come from difficult and challenging backgrounds, which is often the case in urban schools (Crow \& Scribner, 2014). Some of the issues students face included being situated in a community with high crime rates, visibility of gang activity, a proliferation of drug activities, prostitution, and a large homeless population. Other issues were students' Latino(a) background rooted in minority status and social/political tensions derived from the fear of deportation, lack of parental engagement with the school, and a lack of parental knowledge regarding college admission processes and financial aid opportunities.

With this contextual backdrop, we identified three themes characterizing the adoption

of the career academy model: the need to try something new in response to a crisis, valuing 
and building upon the premises of small learning communities, and the role of community context.

A Crisis and the Need to Try Something New. What were the critical considerations for adopting the career academy model? It appeared the adoption of the career academy model stemmed from a crisis in student enrollment in the mid-1990s and the desire to try something new. As reported by Mr. Gonzalez, a school board member, the school district was growing at a rate of 1000 students every year, pushing the overall enrollment to about 35,000 students at the time of this study. The enrollment overflow created a strain on the district's capacity to serve students. As such, the district needed additional school facilities to house students and found a creative solution in one of the most unlikely places, a shopping mall. A shopping mall had slowly emptied after two anchor stores closed. The facilities of this shopping mall provided a timely opportunity for adding ready-made building infrastructure in the school district. Mr. Gonzalez, recounted how this alternative solution was seized:

This complex used to be a former shopping center, and as you probably know, or have been told, this was, I think the [Giant Retail Store] big box. The other end of the complex was the [Other Giant Retail Store] big box. This end of the building was approved for renovations. They'd already created a temporary elementary school in the mall next door, but it was under a waiver because it didn’t meet the earthquake seismic standards. The funding, in part, was used to create the Victory Academy high school complex, this portion of the complex. There were multiple funding tools that were used to make it all happen.

Upon securing access to the shopping mall, the district wanted to try something new as an alternative to the traditional comprehensive schools. This was, in part, due to the restrictions of the shopping mall building infrastructure, which was better suited for accommodating small learning communities. At that time, the consensus was to build school programs around the career academy model with one of them offering multiple technology tracks related to multi-media, digital communication, and digital film production. The focus on technology and film production came about because there was a conference center and a movie theater already available in the building, so the required space needed to showcase films were in place. With some retrofitting, the building was ready as an alternative design to the comprehensive school format. Mr. Gonzalez, the School Board Member, continued recounting the approach:

That's how all these things started back then. It was seen, truly, as an alternative to the large, comprehensive high schools that we have in the district, which we had four at the time. [...] A lot of kids would get lost in big, comprehensive schools. I call it hiding in schools. That was one of the things I found in my research was a lot of faculty and students are able to hide in a large, comprehensive school. They stay in their room. Sometimes, they go off campus, and nobody even knows they're gone, as long as they don't cause any problems, right? Nobody causes problems, they just skate through the system. 
According to school and district stakeholders, the superintendent at the time had a vision to provide the community with a twenty-first century school, a school different than many comprehensive high schools, with no sports, and offering parents and students a choice to attend a school where all classrooms were equipped with computers and other emerging technologies. To make it happen, the district applied for state and federal grant funding and received a total of twelve million dollars for the purpose of creating career academies in the district. Under the new vision for the academy, the principal could select the top teachers in the district, and when the school opened there was a 200-student waiting list based on an application enrollment process. By all accounts, the school became a success in the community and enrollment grew from 300 to about 550 students in a few years. The pinnacle of the school's popularity came about around 2009 when a student film highlighting the socioeconomic struggles in the community was identified and used in President Obama's speeches. Then, a new crisis cycle came about. Dr. Santiago, the school principal, explained:

What ended up happening was after the initial pot of money dried up, what they didn't pencil in is a sustainable factor in it so the computers started getting dated right around five years, six years. There was no money for replacement because the initial money that was used was a one-time money, and so from about 2006, 2007, the school started now to decline. It declined academically. It declined in enrollment.

Concomitantly, around 2010 the district began to lose students, and the impact was also seen in the academy, which no longer had a waiting list of students wishing to enroll. The declining enrollment crisis prompted the district to close the elementary school in the building but left Victory Academy in place. However, the declining enrollment trend brought about a change in student population with a turn to less academically prepared students. Coupled with technology equipment in need of updating, it was time to try something new again. As a result, Dr. Santiago was brought in to get the school back on track. He described his charge at the time:

When I came in, my superintendent specifically told me I need you to fix that specific issue, which is the mindset issue of teachers. The mindset issue was that these kids don't belong here. These kids are-they're not Victory caliber students. In addition to that, I was also asked to move from just being a tech school to making it a film school [only].

The original curricular design of the academy had been built around technology and a mathematics pathway aligned with a more academically prepared student population. When the new principal, Dr. Santiago, came on board in 2014, he realized the mathematics pathway no longer aligned with the student population and therefore had to refocus the curriculum. In addition, as charged by the school district, he had to narrow the technology focus of the academy into filmmaking only to make enrollment more appealing for students. Although there were no filmmaking companies in the community, their thinking at the time was still informed by the premise that there was a large film industry in the greater geographical region. Thus, Dr. Santiago had to secure resources to update the 
technical equipment in dire need of a refresh. Otherwise, as Dr. Santiago pointed out, "You can't call yourself a tech school when your newest computer is eight years old.”

Building Upon the Premises of Small Learning Communities. What were the design features valued by stakeholders? Currently, Victory Academy is a school of choice, and we learned that students typically chose to enroll because of the small size, reputation for providing a safe environment, and its academic success. As such, there were three prominent features associated with small learning communities that were valued by stakeholders and used to build upon the design structure of the academy: keeping a small student population, focusing on high student expectations and individual attention, and emphasizing the role of thematic curriculum and instruction.

Keeping the small school size. When discussing the restructuring of schools in the district due to declining enrollments, there was a consensus on the importance of keeping Victory Academy in place and ensuring that it kept a small student population of about 300 students. All stakeholders, including parents, school board members, district personnel, and school staff, talked about the benefits of a small school size. For example, Ms. Rodriguez, a parent, pointed to the following:

I think students tend to get a little lost in a larger setting. They have approximately 3,000 to 5,000 students in a comprehensive site. Here there's an opportunity-students can't hide from staff, vice versa. There is that constant dialogue, whether it be in the classes, or in the hallways, and I think that's good.

Mr. Young, an advisory board member, was another voice confirming the benefits of a small school size and noted that it provides an opportunity for school staff and students to develop a strong sense of community and get to know each other. Mr. Gonzalez, a school board member, agreed when he said, "It's very different. [The academy] is not as cliquish as most comprehensive schools. It's more of a tight-knit community.” This narrative was identified in conversations with stakeholders and confirmed a shared appreciation for the small school size as a factor in providing a familial environment in the academy.

Another important element of the school size was the culture that evolved out of staff and students working together indoors in a small place. The culture, as recognized by all stakeholders, was appreciated because it provided a sense of safety and social acceptance of students from all backgrounds. In a community with a high rate of crime and known for prostitution in the surrounding area, the small school offered a safe haven with no bullying issues where students felt welcomed and a sense of belonging. School staff shared their take on the role of the small school size:

Many of our students still come to us because they don't feel safe at the other schools. We don't have any bullying issues. We don't have any social media drama like the other schools do. Kids are normed and conditioned pretty easily in terms of we're a school where you come to learn and not just to socialize. (Dr. Santiago, school principal)

There's no social class structure here. In a traditional high school, you've got your jocks and your cheerleaders and then your nerds. Everyone's equal here because we don't have an organized sports program. We don't have any cheerleaders, so the people don't 
get to wear their status costumes around the school and flaunt them. Everybody feels like they're an equal. (Mr. Talbot, teacher)

While the appreciation for the small size of Victory Academy was articulated, a small school is not for every student. Stakeholders noted that some students prefer bigger comprehensive schools for a variety of reasons. Some students prefer larger schools because of the opportunity for a heightened social life, while for other students, they may appreciate the access to athletics. Thus, the element of choice and decision to be a part of a small school plays a role in shaping the culture of safety, acceptance, and familial bonds in the academy. In this regard, Ms. Warren, the deputy superintendent, highlighted the element of choice in attending a small school:

If you didn't want to go to a big school, and you weren't going for that program, you could choose one of our other two academies. Easier to get to, closer access, so forth and so on. They are going because it's small. They're going because it has a great reputation. It is one of our highest achieving schools, academically, on all counts. They're going for that, as well.

Focus on high student expectations and individual attention. Although the student population has changed, the focus on high student expectations has remained a key feature of the school design and culture. This focus has been possible due to the small school size and the fact that students want to be part of the academy. As the principal Dr. Santiago noted, students "choose to stay because they know what they're getting into, which is a culture of high expectations, a culture where bad behavior is simply not tolerated.” This emphasis is based on a shared understanding of the local community, which predominantly consists of a Latino(a) population with low-educated families. As such, the culture of high expectations has translated into the academy's reputation as being academically demanding and as a place underscored by respect to the physical space and to everyone. As a result, the school was clean all around, with no graffiti and no issues of bullying. This focus on high student expectations is pervasive among stakeholders including parents, school staff, and district personnel, and has been the catalyst to set high goals for high school graduation and prepare students for college and work. For example, Ms. Jenkins, a school district administrator, offered the following perspective:

Ultimately the goal is to prepare kids to be college and career ready. Ultimately the goal is to give these kids a skill set that they can carry on with them and eventually, like I said, go to some type of dual enrollment, go to some type of program where they've leaving with some basic skills that they can continue on and/or get college credit for what they're doing.

With this collective focus, the academy had a graduation rate of $96 \%$, and $100 \%$ of graduates applied to two- and four-year colleges. According to the assistant principal, Mr. Ladon, students bought into that mindset and came to believe that, "I'm coming here to be successful. I'm coming here with a goal of going to college.” Ms. Rivera reinforced this notion, indicating that students have essentially no choice but to buy into the college-going mindset because she makes "sure that $100 \%$ of the students apply to college." Applying to college is mandatory and the underlying policy was for students to apply to at least two 
colleges. In that regard, it was well known that Ms. Rivera met with all senior students and their parents to discuss college applications and related requirements such as financial aid considerations. Parents, such as Ms. Rodriguez, appreciated the school focus on college preparation:

One of the things that's great about the school is seeing all the students leave here knowing what they're going to do afterward.... They already know that they're going to this college of that university. The students don't leave here wondering what they're going to do next.

The focus on high expectations and the possibility to work with individual students and their parents seemed to be more feasible given the small school size. To reach a high graduation rate and prepare students for college, the school culture of high expectations was supported with a concerted strategy to help struggling students. The approach of the staff at Victory Academy was to identify the lowest $20 \%$ of students in terms of academic performance and provide them with targeted after-school tutoring and other services. The principal, assistant principal, and the counselor provide tutoring to students with the understanding that each student had different needs. The assistant principal, Mr. Ladon explained how this works:

Looking at data-Dr. Santiago [the principal] is really good at that. Well, he's created a formula where we take academic history, current academic grades, reading levels, attendance, tardies, and, basically, say who would be our lowest performing-I'll put that in quotes-"lowest performing" $20 \%$ of the students on campus who are the highest risk of not graduating. It's basically 63 students, so it's 21\%. For example, I have 21 students that I regularly meet with. We sat down with their parents. We offer them tutoring Tuesdays and Thursdays. We actually go into the community and get food provided so that way, when we're done, we could feed the students.

Tutoring is provided four days a week after school. Students are then monitored, and their improvement in performance celebrated to boost their motivation. This approach is known and recognized by district personnel and parents. As such, there is appreciation for the targeted individual support and acknowledgement that this is likely feasible because of the small student population.

Role of curriculum and instruction. The curricular focus on filmmaking and the role of public instruction were important design features of Victory Academy valued by stakeholders. Initially, the curricular theme had been broadly defined around technology including filmmaking, graphic arts, game design, and programming. Then, with declining enrollment in the district and change in the student population in the academy, it became obvious that it was not feasible to keep all tracks available to students and the district decided to narrow down the curricular theme to filmmaking. The focus on technology remained an important element of the academy, but there was a need for streamlining the curricular theme to filmmaking only, to make enrollment more appealing for students and more efficient to run for school staff given the small school size and limited resources. As noted by the principal, Dr. Santiago, the initial curricular design did not quite align with the small school population: 
...it became very difficult to meet the NAF requirements, while at the same time truly implement them to fidelity on site. The media production is the only one who really married well with the NAF requirement. We used to have various tracks, but again, that process, I thought-in my professional opinion, wasn't necessarily thought-out very well because you can't have that many pathways when you only have 400 students, right?

In addition to restructuring the curricular theme to only one track (filmmaking), the district wanted to maximize the assets already available within the building and community. As Mr. Santos, a school district administrator, noted, there was a movie theater in the former shopping mall; thus, the school could utilize the former movie theater to showcase student films. Further, building on the notoriety of the film industry in the region, it made sense to the school leaders to select filmmaking as the academy theme while keeping a general emphasis on technology. This design decision has helped with the promotion of the career academy and to attract the attention of students around the possibility of learning about and working on filmmaking projects. On that note, Ms. Rivera, the School Counselor, reinforced this perspective when she said:

If there's an emphasis, just like we have film, the students come here with an interest, and I feel like it encourages them to want to come to school, because they know they're gonna' [sic] take that class that they really love. It enforces students to be passionate about their education. I feel like a lot of the kids here are very passionate about coming to school and being part of the programs that we have here.

From an instructional perspective, filmmaking has offered an outlet for curriculum integration and student work focused on storytelling regarding personal, family, and community issues. Students concentrating in the filmmaking track learn about all aspects of film production. In addition, students design and develop short movies that are showcased at a community festival hosted at the adjacent movie theater. Students taking filmmaking courses were also engaged in producing short videos featuring weekly news for the school and filming special events for the school district. All of the stakeholders we interviewed agreed that filmmaking was a medium that enabled students to engage in in all aspects of visual storytelling and production as an outlet for reflection on social issues within the community.

A complementary feature of the academy was its emphasis on public instruction. That is, the design of the building and classrooms allows for instruction to be visible to anyone walking around the school. Mr. Talbot, a teacher, pointed out that "the physical plant is basically in the shape of a donut," and there was a general agreement that the physical environment created the conditions for instruction as a public practice whereby teachers and students could showcase their levels of student engagement using effective pedagogical approaches. It also provided an opportunity for administrators to monitor student engagement and the nature of teaching activities. As school staff noted, unlike other schools where students can get lost behind closed classrooms, it was difficult to hide in Victory Academy. Dr. Santiago, the principal, explained the role of public instruction in the academy: 
Every classroom has a wall of glass so it almost-imagine if we had one here and people were passing by - this meeting would probably look different. Our body language would probably change. I mean, as teachers I think it de-privatizes their practice, so you aren't really like the king or queen of your own classroom. It's everyone's classroom. Students feel the same way, that-I can, literally, in 2 minutes observe $100 \%$ of my students, which if you gave a principal the option to do that in any school, it'd be difficult because our time is so limited, and-our schedules are so erratic that walk-throughs kind of take a back seat in many schools. Here it goes to the forefront because that's what changes the student's experience. I think that structural component really lends itself to the way we operate.

Mr. Ladon, the assistant principal, agreed with Dr. Santiago on the role of public instruction in the academy. He further noted that being an indoor campus where students can witness the kind of work everyone is engaged in also serves as a source of motivation for learning technology skills related to filmmaking (e.g., media production, graphic arts). In turn, he further noted that when parents see the movie theater, attend the film festival, and are able to see what students are doing in the classroom, they too gain an appreciation for filmmaking as the curricular theme and for the public instruction.

Defining and sustaining the implementation of design features for the career academy has not been easy in terms of curriculum and instruction. To ensure the fidelity of the career academy model implementation, the district sought participation in the NAF network. However, there have been issues with district and school liaison continuity with NAF and meeting the requirements of having work-based learning opportunities (e.g., internships) available for students. Restructuring the focus of the academy to filmmaking was seen a step in the right direction, but the availability of work-based learning experiences has remained a challenge. In addition, as a school of choice, there is no feeder pipeline for assured enrollment. Further, a small school has meant that staff have had to wear many hats, teachers teach more courses, and students have fewer electives to choose from. As Ms. Jenkins, a district administrator , put it, a small school can be a case of good and bad news:

Some of the challenges are that it's a small school. That's good and bad. Many of the challenges are also attributes. Do you know what I mean? The good news is, it's a small school. The bad news is, it's a small school. The good news is you have a really, really motivated student body. The bad news, we really don't have a feeder area. It's a choice school. Kids come by choice.

Mr. Foster, a teacher, confirmed this perspective, pointing out that with a staff of 16 teachers everyone must play additional roles. In his case, he reported having five different class preparations. Ms. Jenkins, another teacher, added that in a small school like Victory Academy "it's really hard to give students the amount of diversity of interesting electives that they want." Mr. Ladon shared that the small school size "creates a family environment, but at the same time, we're also restricted on the master schedule on how many class offerings we could give." 
Challenging Community Conditions. In addition to the challenges inherent to small learning communities, the historical social and demographic conditions in the community have also contributed to how the academy has been designed and implemented. Such conditions are also helpful in understanding the appreciation for an indoor small school with a curricular focus on technology. The analysis of interview data and documentation of school and community indicators made it evident that the reputation of the community for high crime and prostitution played a role in keeping a small school in operation. The dire reputation of the community was acknowledged by all participants during the interviews. For example:

Things in our community aren't always the greatest. What is highlighted in the news about Victory City, or the nearby communities, isn't the achievements that our kids are doing, but the negativity, the homeliness, the crime... (Ms. Lopez, postsecondary partner).

This reality inspired the development of an alternative to the traditional comprehensive high school in the community, and thus the development of a small-sized career academy in an indoor facility to provide a safe place for learning.

In turn, the population in the community surrounding the academy was represented by a high percentage of low-income families of Latino(a) heritage, limited English speaking ability, and low education level. Further, parents were often unable to get involved in school-related activities. Within that context, parents and students from these families represent an important segment of the academy constituency who have been identified as requiring additional supports. Dr. Santiago summarized this by stating:

We're about a 91\% free and reduced lunch school site, 96\% Hispanic. The district as a whole is upwards about $85 \%$ Hispanic. I think, at the last survey, $60 \%$ of my parents don't speak English. About 15\% have a college education, and the difference have only a high school education. One of the challenges is that parent involvement here is very, very limited [and] it's just difficult to get a parent involved when a good chunk of our parent base is a single parent or when you have multiple families living in a home to be able to make ends meet.

"Just thinking about it,” Ms. Rivera said, "makes me choke because the challenges that students face are hard.” To address this issue, students coming from these families are often identified in the pool of students at-risk of underperforming in the academy or in need of other supports. This situation became more evident during the crisis related to declining enrollment, which resulted in a wave of new students with a higher proportion in need of remedial academic education to succeed in the academy. Thus, the focus on high student expectations also included specific strategies to help at-risk students through after-school tutoring, transportation, and access to a food pantry for their families.

Finally, it was evident in our analysis that the alignment of the curricular theme and local support was problematic from a sustainability perspective. Although the focus on technology with specific emphasis on filmmaking makes curricular and instructional sense, the need for periodic technology updates was a lingering issue. This is especially important in an area where technology advances rapidly. The benefits of acquiring script writing, 
video production, and graphic arts skills, even when students may not pursue related careers, are appreciated by stakeholders. On the other hand, the key to providing students with relevant technical skills lies on access to up-to date equipment, and recurring funding for maintenance and upgrade is an issue. This challenge was summarized by Dr. Santiago:

...the newest computer at the time when I came on board in summer of '14 was eight years old. My newest camera was about the same. Funding becomes a challenge when you're meant to be a film school, but you don't have the equipment and other resources essential to get that done. What ended up happening was after the initial pot of money dried up, what they didn't pencil in is a sustainable factor in it so the computers started getting dated right around five years, six years. There was no money for replacement because the initial money that was used was a one-time money...

"We're trying to fight for more funding, and the district still doesn’t understand," said Mr. Smith, a teacher. A related issue is the lack of access to employers in the film industry in the community. The film industry is represented by large corporate studios in the region but is not directly accessible for local students seeking to gain work experience through job shadowing and/or internships. The curricular focus of the academy was restructured to filmmaking given the technology emphasis of the academy and infrastructure for showcasing films in the building. However, given the lack of a pool of employers in the community engaged in film production and the issue of not providing students with transportation to local employers, there were no opportunities for students for systematic participation in paid internships or other work-based learning activities (e.g., job shadowing). In this regard, students are unable to reap the benefits of work-based learning experiences, which have been identified as critical for boosting career readiness and employability skills. Ms. Warren, the school district deputy superintendent, noted that "the challenge is how we get students easier access to work-based learning experiences. Bringing those experiences to them.” Dr. Santiago, school principal, best summarized the challenge:

...so I'm making films, and I need to access industry when there is no industry around us, and there is no budgeting to take my students to industry. I wish there was something right here where we could get our kids for that support. Some of our kids now getting into media technology, yeah, they've seen a movie, but they've never really been on any movie set.

The community conditions and sustainability issues associated with the need for recurring funding for technology updates and access to work-based learning opportunities in filmmaking were often discussed by stakeholders as they represent important components of the career academy design.

\section{Discussion and Conclusions}

The development and implementation of Victory Academy aligned with the literature on school restructuring and small learning communities. From research on school restructuring we learned that successful schools make changes in response to a crisis 
requiring bold steps for improvement (Newman \& Whelage, 1995; Ryan, 2011). This is also a common denominator in the literature of career academies, which are often started as a means to improve lagging student performance (Brand, 2009; Stern, Wu, Dayton, \& Maul, 2005). In the case of Victory Academy, what were the critical considerations for the adoption of the career academy model? In this community, the adoption and adaptation of the model stemmed from a two-fold interest: to respond to growing enrollment in the district and the need to address college and career readiness. Thus, there was an agreement to look for an alternative to the comprehensive high school and seize on the principles of small learning communities to establish Victory Academy. The initial consensus aligned with a key component of school restructuring, indicating that shared agreement among stakeholders on the vision for improvement is fundamental to successful implementation (Adelman \& Taylor, 2003; NCAC, 2013; Newmann \& Wehlage, 1995). In this case, the career academy model fit the desire to improve college and career readiness and the local need for a small school suited for a retrofitted shopping mall.

In turn, what were the design features viewed as fundamental to the career academy model? The case of Victory Academy further aligned with the second principle of school restructuring, which calls for a shared understanding of the important design features and organizational supports (Hernandez-Gantes \& Brendefur, 2003; Newmann \& Whelage, 1995). It became evident in our research that the small school size was a design feature valued by stakeholders. As such, they ensured the school remained small enough to provide individual student attention and promote high expectations. Another design feature viewed as critical was the use of technology including filmmaking and other tracks to anchor curriculum and instruction. In this small school environment, the goal was to emphasize college and career readiness around the use of technology, as well as to make teacher and student work visible and accountable through public instruction. Further, the administrative staff decided to provide targeted and continued student support to ensure that every student had a chance to succeed in school by transitioning to college. The use of technology as the underlying curricular theme was highlighted as a critical foundation that provide a platform for curriculum and instruction in the academy.

Finally, what was the role of the community context in adopting and shaping the career academy model? When another crisis came along in the district, the important role of conditions external to the school became evident. According to school restructuring research, schools that account for local conditions and factors are more likely to sustain successful implementation (Alfeld et al., 2013; Newmann \& Whelage, 1995). In the case of Victory Academy, the local conditions have been a challenging factor impacting implementation. When enrollment in the district began to decrease, district and school stakeholders decided to keep the small career academy in place and streamline the curricular tracks to only filmmaking. While keeping the career academy in operation was welcomed, curricular decisions turned into a top-down approach with novel directives given to a new principal. Declining enrollment also changed the student population and the parent base, which exacerbated the lack of parental involvement and the need for remedial education. In addition, funding became a lingering issue given the periodic need to upgrade technology. Concurrently, although there is a large film industry in the greater geographical area, the lack of filmmaking companies in the immediate community prevented the school 
from providing students with relevant work-based learning opportunities. As such, the best the school can do is to emphasize in-school projects involving the production of short films and complementary applications (e.g., graphic arts, script writing, production). Although these project are relevant and engaging for students, this emphasis on filmmaking creates a mismatch with the original intended curricular theme of information technology. In the current form, the focus on filmmaking is aligned with the CTE career cluster of Arts, A/V Technology, and Communications. Therefore, while the school sought to improve the career readiness of their students, they departed from the initial focus on IT, which may explain the issues related to meeting NAF requirements. In addition, the school does not have the connections needed to provide students with work-based learning opportunities that are essential in developing students' employability and technical skills needed to pursue college majors and/or careers in film (Hernandez-Gantes et al., 2018; Fletcher et al., 2018; Hernandez-Gantes et al., 2017; Stone \& Lewis, 2012; Stringfield \& Stone, 2017).

Although the school boasts a very high graduation rate and practically all students enroll in two- and four-year colleges, we found that good intentions are not enough to guarantee the successful implementation of a career academy. Evidence from the case study of Victory Academy suggested that decisions on development and implementation are not a one-time process, despite the promising premises of the career academy model and small learning communities. The process is becomes obviously fluid over time and requires tweaking along the way when new crises come along. In this case the role of local conditions is an important consideration along with a shared understanding of stakeholders during revisions to ensure buy-in from all parties involved.

The school has attempted to account for the local context related to the particular challenges brought about by the social and economic factors around the Latino(a) population in the area. However, under the local conditions, the promotion of college and career readiness has become one-sided toward college preparation given the fact that there is no filmmaking industry in the immediate community to provide related work-based learning experiences. Although filmmaking appears to provide a useful platform for curriculum and instruction constrained to in-school projects, the fit with local industry is not there and should be revisited. As such, local stakeholders have been mindful of changes in local conditions and the need to make changes in the academy design. At issue is that in the process of identifying and moving forward with changes, a shared consensus is bypassed in favor of a more expeditious top-down approach. While changes get done, some issues do not appear to be fully resolved such as the role of filmmaking as the curricular theme.

In conclusion, we learned that the development of Victory Academy followed the pattern highlighted in the literature on school restructuring in the context of small learning communities. The push for college and career readiness has become a major driver for change, while small learning communities, such as career academies, make for promising alternatives for schools and districts in their quest to respond to a crisis involving student performance. We also learned that good intentions are not enough to guarantee the consistent fidelity of implementation as originally planned. When new crises come along, input from all stakeholders may be shortchanged and turned into a top-down approach. Further, the role of local conditions should be carefully considered to account for particular 
needs of parents and students. In addition, the availability of local support for work-based learning experiences aligned with the curricular theme should be thoroughly assessed for sustainability purposes prior to proceeding with actual implementation. Otherwise, given the lack of work-based learning opportunities, although students may still learn some related technical skills in school, their readiness to transition to filmmaking career pathways beyond high school may be limited.

The findings of our study were derived from a single case study in the context of a high school career academy operating under unique community conditions. Thus, although the results aligned with relevant literature, they may not be representative of how career academies operate in general in the US. As such, further research documenting the adoption and adaptation of the career academy model under different community conditions and geographical locations is warranted.

Note: This report is based on work supported by the National Science Foundation's Innovative Technology Experiences for Students and Teachers (ITEST) program under grant number \#1614707. Any opinions, findings, and conclusions or recommendations expressed in this publication are those of the authors and do not necessarily reflect the views of the National Science Foundation.

\section{References}

Achieve. (2016). The college and career readiness of high school graduates. Washington, DC: Author.

Adelman, H. S., \& Taylor, L. (2003). School-community relations: Policy and practice. In M. Fishbaugh, G. Schroth, \& T. Berkeley (Eds.), Ensuring safe school environments: Exploring issues \& seeking solutions (pp. 107-132). Mahwah, NJ: Lawrence Erlbaum.

Alfeld, C., Charner, I., Johnson, L., \& Watts, E. (2013). Work-based learning opportunities for high school students. Louisville, KY: National Research Center for Career and Technical Education. Retrieved from http://www.nrccte.org/sites/default/files/publicationfiles/nrccte_work-based_learning.pdf

Barton, P. (2006). High school reform and work: Facing labor market realities. Princeton, NJ: Educational Testing Service.

Bitterman, A., Gray, L., \& Goldring, R. (2013). Characteristics of public and private elementary and secondary schools in the United States. Results from the 2011-2012 Schools and Staffing Survey (NCES 2013-312). U.S. Department of Education. Washington, DC: National Center for Education Statistics.

Brand, B. (2009). High school career academies: A 40-year proven model for improving college and career readiness. Nashville, TN: National Career Academy Coalition.

Cappelli, P. (2008, Summer). Schools of dreams: More education is not an economic elixir. Issues in Science and Technology, 24(4), 60-64.

Carnevale, A. P., Smith, N., \& Strohl, J. (2010). Help wanted: Projections of jobs and education requirements through 2018. Georgetown University Center on Education and the Workforce. Retrieved from https://cew.georgetown.edu/cew-reports/help-wanted/\#report

Castellano, M., Sundell, K., Overman, L. T., \& Aliaga, O. A. (2012). Do career and technical education programs of study improve student achievement? Preliminary analyses from a rigorous longitudinal study. International Journal of Educational Reform, 21, 98-118. 
Conchas, G.Q., \& Clark, P.A. (2002). Career academies and urban minority schooling: Forging optimism despite limited opportunity. Journal of Education for Students Placed at Risk, 7(3), 287-311.

Conley, D. T. (2012). A complete definition of college and career readiness. Eugene, OR: Educational Policy Improvement Center.

Crow, G. M., \& Scribner, S. P. (2014). Professional identities of urban school principals. In R. Milner \& K. Lomotey (Eds.), Handbook of urban education (pp. 287-304). New York, NY: Routledge.

Finch, C. R., \& Crunkilton, J. R. (1999). Curriculum development in vocational and technical education: Planning, content, and implementation. Boston, MA: Allyn and Bacon.

Fletcher, E., \& Cox, E. (2012). Exploring the meaning African American students ascribe to their participation in high school career academies and the challenges they experience. The High School Journal, 96(1), 4-19. https://doi.org/10.1353/hsj.2012.0017

Fletcher, E., Warren, N., \& Hernández-Gantes, V.M. (2018). Preparing high school students for a changing world: College, career, and future ready learners. Career and Technical Education Research, 43(1), 77-98. https://doi.org/10.5328/cter43.1.77

Hernández-Gantes, V. M. (2016). College and career readiness for all: The role of career and technical education in the US. In D. Wyse, L. Hayward, \& J. Pandya (Eds.), SAGE handbook of curriculum, pedagogy and assessment (Vol. 2, pp. 674-689). London: SAGE.

Hernández-Gantes, V., \& Blank, W. (2009). Teaching English language learners in career and technical education programs. New York: Routledge.

Hernández-Gantes, V. M., \& Brendefur, J. (2003). Developing authentic, integrated, standardsbased mathematics curriculum: [More than just] an interdisciplinary collaborative approach. Journal of Vocational Education Research, 28(3), 259-284.

Hernández-Gantes, V. M., \& Fletcher, E. (2013). The need for integrated workforce development systems to broaden the participation of underrepresented students in STEM-related fields. In R. Palmer \& L. Wood (Eds.), Community college and STEM: Examining underrepresented racial and ethnic minorities. New York: Routledge.

Hernández-Gantes , V.M., Jenkins, S., \& Fletcher, E. (2017). Promoting active and sustained school-business partnerships: An exploratory case study of an IT academy. Journal of Research in Technical Careers, 1(2), 26-35.

Hernández-Gantes , V.M., Keighobadi, S., \& Fletcher, E.C. (2018). Building community bonds, bridges, and linkages to promote the career readiness of high school students in the United States. Journal of Education and Work, 31(2) 190-203. https:/doi.org/ 10.1080/

13639080.2018.1434871

Hernández-Gantes, V. M., Phelps, L. A., Jones, J., \& Holub, T. (1995). School climate in emerging career-oriented programs: Students’ perspectives. Journal of Vocational Education Research, 20(2), 5-26.

Karp, M., Calcagno, J., Hughes, K., Jeong, D., \& Bailey, T. (2007). The postsecondary achievement of participants in dual enrollment: An analysis of student outcomes in two states. St. Paul, MN: National Research Center for Career and Technical Education, University of Minnesota.

Kemple, J. J. (2008). Career academies: Long-term impacts on labor market outcomes, educational attainment, and transitions to adulthood. New York, NY: Manpower Demonstration Research Corporation.

Kemple, J. J., \& Snipes, J. C. (2000). Career academies: Impacts on students' engagement and performance in high school. Manpower Demonstration Research Corporation. Retrieved from https://www.mdrc.org/sites/default/files/Career_Academies_Impacts_on_ 
Students.pdf

Kuo, V. (2010). Transforming American high schools: Possibilities for the next phase of high school reform. Peabody Journal of Education, 85(3), 398-401. https://doi.org/10.1080/

0161956X.2010.491709

Loera, G., Nakamoto, J., Oh, Y.J., \& Rueda, R. (2013). Factors that promote motivation and academic engagement in a career technical education context. Career and Technical Education Research, 38(3), 173-190. https://doi.org/10.5328/cter38.3.173

National Academy Foundation. (2014). Statistics and research: 2013-2014. Retrieved from http://naf.org/statistics-and-research

National Academy Foundation. (2017a). NAF track. Retrieved from https://naf.org/wpcontent/uploads/2017/10/NAFTrack-Updated-9-25-17-1.pdf

National Academy Foundation. (2017b). Together transforming the future. Retrieved from https://naf.org/wp-content/uploads/2017/10/2016-2017-Impact-Report.pdf

National Academy Foundation. (2017c). Scaling impact taking corporate engagement to the next level. Retrieved from https://naf.org/wpcontent/uploads/2017/02/ScalingImpact_Dallas.pdf

National Career Academy Coalition. (2013). National standards of practice for career academies. Nashville, TN: Author.

National Center on Education and the Economy. (2007). Tough choices or tough times: The report of the New Commission on the Skills of the American Workforce. San Francisco: Wiley.

National Center for Public Policy and Higher Education. (2004). Measuring up 2004: The state report card on higher education. San Jose, CA: National Center for Public Policy and Higher Education.

Newmann, F. M., \& Wehlage, G. G. (1995). Successful school restructuring: A report to the public and educators. Madison, WI: Center on Organization and Restructuring of Schools.

Page, L., Layzer, C., Schimmenti, J., Bernstein, L., \& Horst, L. (2002). National evaluation of smaller learning communities: Literature review. Cambridge, MA: Abbott.

Partnership for 21st Century Skills (2011). A framework for 21st century learning. Retrieved from http://www.p21.org

Resnick, L. B., \& Hall, M. W. (1998). Learning organizations for sustainable education reform. Daedalus, 127(4), 89-118.

Ryan, A. (2011). Education for sustainable development and holistic curriculum change. A review guide. Heslington, York, United Kingdom: The Higher Education Academy.

Secretary's Commission on Achieving Necessary Skills (SCANS). (1991). What work requires of schools: A SCANS report for America 2000. Retrieved from https://wdr.doleta.gov/

SCANS/whatwork/

Silverberg, M., Warner, E., Fong, M., \& Goodwin, D. (2004). National assessment of vocational education. Final report to Congress. US Department of Education.

Stake, R. (2006). Multiple case study analysis. New York: Guilford.

Stern, D., Wu, C., Dayton, C., \& Maul, A. (2005). Learning by doing career academies. Berkeley, CA: Career Academy Support Network.

Stern, D., Dayton, C., \& Raby, M. (2010). Career academies: A proven strategy to prepare high school students for college and careers. Berkeley, CA: Career Academy Support Network.

Stipanovic, N., Lewis, M., \& Stringfield, S. (2012). Situating Programs of Study within current and historical career and technical education reform efforts. International Journal of Educational Reform, 21(2), 80-97. 
Stone, J. R., III. (2017). Introduction to pathways to a productive adulthood: The role of CTE in the American high school. Peabody Journal of Education, 92(2), 155-165. https://doi.org/10.1080/0161956X.2017.1302207

Stone, J. R., III, \& Alfeld, C. (2006). The neglected majority - Revisited. Journal of Career and Technical Education, 21(2), 61-74. https://doi.org/10.21061/jcte.v21i2.658

Stone, J. R., III, \& Lewis, M. V. (2012). College and career ready in the 21st century: Making high school matter. New York, NY: Teacher's College Press.

Stringfield, S., \& Stone, J. R., III. (2017). The labor market imperative for CTE: Changes and challenges for the 21st century. Peabody Journal of Education, 92(2), 166-179. https://doi.org/10.1080/0161956X.2017.1302207

Symonds, W.C., Schwartz, R., \& Ferguson, R.F. (2011). Pathways to prosperity: Meeting the challenge of preparing young Americans for the 21st century. Cambridge, MA: Harvard University.

Wertz, F. (2005). Phenomenological research methods for counseling psychology. Journal of Counseling Psychology, 52(2), 167-177. http://dx.doi.org/10.1037/0022-0167.52.2.167 